- Original Article

\title{
Use of Hypnotics and Risk of Cancer: A Meta-Analysis of Observational Studies
}

\author{
Do-Hyoung Kim ${ }^{1}$, Hong-Bae Kim ${ }^{1,2, *}$, Young-Hyo Kim¹, Ja-Young Kim \\ 'Department of Family Medicine, MyongJi Hospital, Goyang, Korea \\ ${ }^{2}$ Department of Family Medicine, Yonsei University College of Medicine, Seoul, Korea
}

Background: Previous observational epidemiological studies have shown inconsistent results on the relationship between hypnotics use and risk of cancer. To determine the association between hypnotics use and risk of cancer, we conducted a meta-analysis of available literature.

Methods: We searched databases PubMed, EMBASE, and the bibliographies of relevant articles to locate additional publications in February 2016. Three evaluators independently reviewed and selected eligible studies based on pre-determined selection criteria.

Results: A total of six observational epidemiological studies including three case-control studies and three cohort studies, which involved 1,830,434 participants (202,629 hypnotics users and 1,627,805 non-users), were included in the final analyses. In a random-effects meta-analysis, compared with non-use of hypnotics, the odds ratio for overall hypnotics use was 1.29 for various cancers (95\% confidence interval, 1.08-1.53). Subgroup meta-analyses by various factors such as study design, type of case-control study, study region, and methodological quality of study revealed consistent findings.

Conclusion: Our findings from a meta-analysis of low-biased epidemiological studies suggested evidence linking the use of hypnotics to an increased risk of cancers. The results should be cautiously interpreted because of considerable heterogeneity with a Higgins $\mathrm{I}^{2}$ value.

Keywords: Hypnotics; Risk of Neoplasms; Meta-Analysis; Observational Study

Received: February 28, 2017, Revised: April 12, 2017, Accepted: April 19, 2017

*Corresponding Author: Hong-Bae Kim https://orcid.org/0000-0001-7450-1412

Tel: +82-31-810-5420, Fax: +82-31-969-0500, E-mail: hongbai96@naver.com 


\section{INTRODUCTION}

Insomnia has detrimental effects on the quality of life in a large subset of the affected population. ${ }^{1)}$ Hypnotics are used for treating insomnia symptoms, and the intake of hypnotics is estimated to range between $3 \%$ and $12 \%$ in general, with a two-fold increase in the intake of hypnotics among the elderly. ${ }^{2)}$ In addition to other hypnotics, benzodiazepines are prescribed in patients with sleep disorder, anxiety, or panic disorder.

Previous in vitro and animal studies have reported controversial findings on the correlation between benzodiazepine use and the risk of cancer. One animal study reported that benzodiazepines increased the risk of thyroid cancer. ${ }^{3)}$ Conversely, in vitro laboratory studies indicated that benzodiazepines might have antitumor effects on colorectal and breast adenocarcinoma cells. ${ }^{4)}$ Epidemiological studies indicated controversial findings on the relationship between hypnotics use and the risk of cancer. For example, a population based case-control study showed no link between benzodiazepine use and the incidence of breast cancer; ${ }^{5}$ in contrast, a large cohort study conducted in 62,186 subjects who underwent benzodiazepine treatment in Taiwan suggested that benzodiazepine use could be associated with an increased risk of brain tumor. ${ }^{6)}$

To date, there are no published quantitative meta-analyses on this issue. In the current study, we examined the associations between hypnotics use and the risk of cancer by conducting a meta-analysis of observational epidemiological studies including case-control studies and cohort studies.

\section{METHODS}

\section{Literature Search}

We searched PubMed and EMBASE using common keywords related to hypnotics use and the risk of or mortality from cancer in February
2016. The search was restricted to publication dates between June 1972 and October 2015. The keywords were as follows: for exposure factors, "hypnotics," "sleep medication," "sleeping pill," "benzodiazepine," "zolpidem," and "zopiclone"; and for outcome factors, "cancer," "tumor," "carcinoma," and "neoplasm". We also searched the bibliographies of relevant articles. We did not restrict the search by publication language. Institutional Review Board approval for the study was not required because the current meta-analysis used data that was already published.

\section{Selection Criteria}

Observational epidemiological studies that met all of the following criteria were included: (1) case-control study or cohort study; (2) investigated the associations between "hypnotics" and "cancer"; and (3) reported outcome measures with adjusted odds ratios (ORs) or relative risks (RRs) and 95\% confidence intervals (CIs). If data were duplicated or shared in more than one study, we included the first published study or the comprehensive study in the analysis. Unpublished studies and abstracts that were only presented in academic conferences or not published in peer-reviewed journals were not included. We made an attempt to contact the authors in case of insufficient data.

\section{Selection of Relevant Studies}

Three of the authors (KDH, KYH, and KHB) independently evaluated the eligibility of all studies retrieved from the databases based on the above selection criteria. If disagreements between evaluators occurred, they were resolved by consensus through discussion.

\section{Assessment of Methodological Quality}

The methodological quality of included studies was based on the Newcastle-Ottawa Scale (NOS) for assessing the quality of case-control studies and cohort studies in meta-analyses. ${ }^{7)}$ The NOS has a star system for scores ranging from 0 to 9 , with three subscales including se-
597 Identified studies from the databases using keywords and bibliographies of relevant articles: PubMed $(n=374)$, EMBASE $(n=219)$, and bibliographies $(n=4)$

\begin{tabular}{|c|c|}
\hline & 206 Exclude duplicate articles \\
\hline \multicolumn{2}{|c|}{391 Articles remaining after excluding duplicates } \\
\hline & 363 Exclude according to selection criteria \\
\hline \multicolumn{2}{|c|}{28 Remaining articles, full text review } \\
\hline & $\begin{array}{l}22 \text { Excluded articles: } \\
\text { Not relevant }(n=3) \\
\text { Psychotropic medication other than hypnotics }(n=6) \\
\text { Investigating mortality from cancer }(n=6) \\
\text { Using opioids with hypnotics }(n=1) \\
\text { Using data from pre-existing cancer }(n=5) \\
\text { Using an acute biomarker as exposure }(n=1)\end{array}$ \\
\hline 6 Case-control stud & ort studies $(n=3)$ included in the final analysis \\
\hline
\end{tabular}

Figure 1. Flow diagram for identification of relevant studies. 


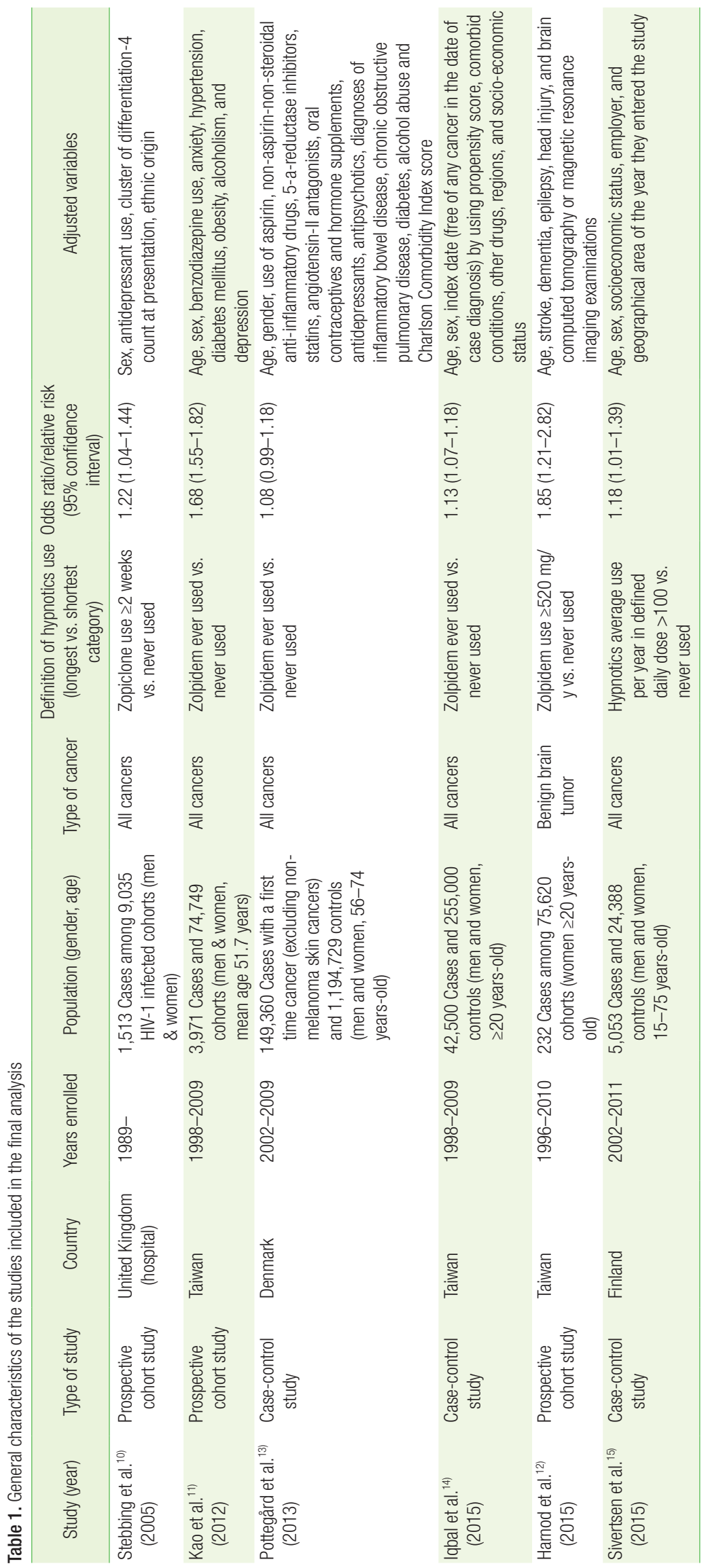


lection of studies, comparability, and exposure. Since the criteria for the high- or low-quality of a study is not well established, we considered a study with a higher score than the mean of each study type as a high-quality study.

\section{Main and Subgroup Analyses}

In the main analysis, we investigated the associations between the use of hypnotics (highest use versus never used) and the overall risk of all cancers by using adjusted data. We also performed subgroup analyses by type of study design (case-control or cohort study), type of cancer, cancer risk, sex, study region (Europe and Asia), duration of hypnotics use, types of hypnotics, cumulative yearly dose, type of case-control study (population-based or hospital-based), and methodological quality of study (high versus low). We also investigated the association between long-term hypnotics use (hypnotics use $\geq 1$ year) and the risk of cancers. We defined short-term hypnotics use as ever used for duration of less than 6 months.

\section{Statistical Analyses}

To calculate OR or RR with its 95\% CI, we used the adjusted ORs or RRs and 95\% CIs in each study reporting the association between hypnotics use (highest use versus never used) and the risk of cancer. We examined the heterogeneity in the results across studies using the Higgins $\mathrm{I}^{2}$, which measures the percentage of total variation across studies. $^{8)}$ The $\mathrm{I}^{2}$ was calculated as follows:

$$
\mathrm{I}^{2}=100 \% \times(Q-\mathrm{df}) / Q,
$$

where Q is Cochran's heterogeneity statistic; and df is the degrees of freedom. Negative values of $\mathrm{I}^{2}$ were set at zero; the $\mathrm{I}^{2}$ value ranges between $0 \%$ (no heterogeneity) and $100 \%$ (maximal heterogeneity). An $\mathrm{I}^{2}$ value $>50 \%$ was considered to indicate substantial heterogeneity. ${ }^{8)}$

We used a random-effects model meta-analysis based on the DerSimonian and Laird method because individual trials were conducted in different populations. ${ }^{9)}$ In the final analysis, we evaluated the publication bias by using Begg's funnel plot and Egger's test. If publication bias existed, Begg's funnel plot would be asymmetrical; or the P-value would be $<0.05$ by Egger's test. We used the Stata SE ver. 13.0 software package (Stata Corp., College Station, TX, USA) for the statistical analysis.

\section{RESULTS}

\section{Identification of Relevant Studies}

Figure 1 presents a flow diagram for identification of relevant studies. We extracted a total of 597 articles by searching two databases and searching relevant bibliographies manually. We excluded 206 articles that were duplicated and additional 363 articles that did not fulfil the selection criteria. As a result, we reviewed the full texts of the remaining 28 articles. Among these, 22 articles were excluded because of the following reasons: not relevant to our analysis $(n=3)$, psychotropic

Table 2. Methodological quality of the studies included in the final analysis based on the Newcastle-Ottawa Scale* for assessing the quality of case-control studies ( $\mathrm{n}=3)^{\star}$

\begin{tabular}{|c|c|c|c|c|c|c|c|c|c|}
\hline \multirow[b]{2}{*}{ Study (year) } & \multicolumn{4}{|c|}{ Selection } & \multirow{2}{*}{$\begin{array}{c}\text { Comparability } \\
\text { Control for important } \\
\text { factor or additional } \\
\text { factor }\end{array}$} & \multicolumn{3}{|c|}{ Exposure } & \multirow[b]{2}{*}{ Tota } \\
\hline & $\begin{array}{l}\text { Adequate } \\
\text { definition of } \\
\text { cases }\end{array}$ & $\begin{array}{l}\text { Represen- } \\
\text { tativeness of } \\
\text { cases }\end{array}$ & $\begin{array}{c}\text { Selection of } \\
\text { controls }\end{array}$ & $\begin{array}{c}\text { Definition of } \\
\text { controls }\end{array}$ & & $\begin{array}{l}\text { Determination } \\
\text { of exposure } \\
\text { (blinding) }\end{array}$ & $\begin{array}{c}\text { Same method of } \\
\text { determination for } \\
\text { participants }\end{array}$ & $\begin{array}{l}\text { Nonresponse } \\
\text { rate }\end{array}$ & \\
\hline $\begin{array}{l}\text { Pottegård et al. }{ }^{13)} \\
\text { (2013) }\end{array}$ & 1 & 1 & 1 & 1 & 2 & 1 & 1 & 0 & 8 \\
\hline $\begin{array}{l}\text { lqbal et al. }{ }^{14)} \\
(2015)\end{array}$ & 1 & 1 & 1 & 1 & 2 & 1 & 1 & 0 & 8 \\
\hline Sivertsen et al. ${ }^{15)}$ & 1 & 1 & 1 & 0 & 1 & 1 & 1 & 0 & 6 \\
\hline
\end{tabular}

$$
\text { (2015) }
$$

*Each study can be awarded a maximum of one star for each numbered item within the selection and exposure categories, while a maximum of two stars can be given for the comparability category.

\begin{tabular}{|c|c|c|c|c|c|c|c|c|c|}
\hline \multirow[b]{2}{*}{ Study (year) } & \multicolumn{4}{|c|}{ Selection } & \multirow{2}{*}{$\begin{array}{c}\text { Comparability } \\
\text { Control for } \\
\text { important factor or } \\
\text { additional factor }\end{array}$} & \multicolumn{3}{|c|}{ Outcome } & \multirow[b]{2}{*}{ Tota } \\
\hline & $\begin{array}{l}\text { Represen- } \\
\text { tativeness of the } \\
\text { exposed cohort }\end{array}$ & $\begin{array}{l}\text { Selection of the } \\
\text { non-exposed } \\
\text { cohort }\end{array}$ & $\begin{array}{l}\text { Determina- } \\
\text { tion of } \\
\text { exposure }\end{array}$ & $\begin{array}{l}\text { Outcome of interest } \\
\text { was not present at } \\
\text { start of study }\end{array}$ & & $\begin{array}{l}\text { Assessment } \\
\text { of outcome }\end{array}$ & $\begin{array}{c}\text { Follow-up long } \\
\text { enough for } \\
\text { outcomes to occur }\end{array}$ & $\begin{array}{c}\text { Adequacy of } \\
\text { follow-up of } \\
\text { cohorts }\end{array}$ & \\
\hline $\begin{array}{l}\text { Stebbing et al. }{ }^{10)} \\
(2005)\end{array}$ & 1 & 1 & 1 & 1 & 1 & 1 & 0 & 0 & 6 \\
\hline $\begin{array}{l}\text { Kao et al. }{ }^{11)} \\
(2012)\end{array}$ & 1 & 1 & 1 & 1 & 1 & 1 & 1 & 0 & 7 \\
\hline Harnod et al. ${ }^{12)}$ & 1 & 1 & 1 & 1 & 1 & 1 & 1 & 0 & 7 \\
\hline
\end{tabular}

Table 3. Methodological quality of the studies included in the final analysis based on the Newcastle-Ottawa Scale* for assessing the quality of cohort studies ( $\mathrm{n}=3)^{*}$

*Each study can be awarded a maximum of one star for each numbered item within the selection and exposure categories, while a maximum of two stars can be given for the comparability category. 
medication use other than hypnotics $(n=6)$, investigating mortality from cancer $(n=6)$, opioid use with hypnotics $(n=1)$, using data from pre-existing cancer $(\mathrm{n}=5)$; and using an acute biomarker as indication of exposure ( $\mathrm{n}=1)$. Finally, the remaining six studies including three cohort studies $^{10-12)}$ and three case-control studies ${ }^{13-15)}$ were included in the meta-analysis.

\section{Characteristics of Studies Included in the Final Analysis}

We identified a total of six observational studies ${ }^{10-15)}$ including $1,830,434$ participants $(202,629$ hypnotics users and 1,627,805 non-users). The participants' mean age was 56.9 years (range, 20 to 102 years). Table 1 shows the general characteristics of the included studies. Three studies were conducted in Europe ${ }^{10,13,15)}$ and the other three in Taiwan. ${ }^{11,12,14)}$ The follow-up period for incident overall cancer ranged between 4 and 12 years, with a median follow-up of 8.3 years. All studies indicated the relationship involving the risk of malignant carcinoma, except one study, ${ }^{12)}$ which investigated the association only for benign brain tumor. In our meta-analysis, studies were conducted for the following types of hypnotics; zolpidem $(n=4),{ }^{11-14)}$ zopiclone $(n=3),{ }^{10,13,14)}$ and benzodiazepines $(\mathrm{n}=2){ }^{13,14)}$

\section{Methodological Quality of Studies}

We assessed the methodological quality of studies included in the final analysis based on the NOS scores. For all studies, the NOS scores ranged from 6 to 8; for case-control studies, the average score was for 7.3; and for cohort studies, the average score was 6.7. The high-quality studies (score of 8 in case-control studies and 7 in cohort studies) included two case-control studies ${ }^{13,14)}$ and two cohort studies (Tables 2, $3)^{11,12)}$

\section{Hypnotics Use and the Risk of All Types of Cancer}

Hypnotics use was significantly associated with an increased risk of cancer in the random-effects meta-analysis of all six studies (pooled OR/RR, 1.29; 95\% CI, 1.08-1.53) (Figure 2). On stratification by study design, both case-control and cohort studies showed a positive correlation between hypnotics use and the risk of cancer.

Table 4 shows the findings from subgroup meta-analyses by various factors. Hypnotics use was consistently associated with an increased risk of cancer in the subgroup meta-analysis by sex, study region, duration of hypnotics use, type of case-control study (population-based or hospital-based), and methodological quality. There was evidence of heterogeneity across studies $\left(\mathrm{I}^{2}=93.9 \%, \mathrm{P}<0.005\right)$.

With regards to the type of hypnotics, zolpidem use showed the strongest risk of cancer (OR, 1.34; 95\% CI, 1.06-1.70) compared to benzodiazepine use (OR, 1.15; 95\% CI, 1.11-1.18) or zopiclone use (OR, 1.11; 95\% CI, 1.04-1.20; $\mathrm{P}=0.01$ for studies including zolpidem versus non-zolpidem) (Figure 3); whereas, heterogeneity was not observed in the zopiclone- and benzodiazepine-user groups $\left(\mathrm{I}^{2}=37.3 \%\right.$ for zopiclone use and $0.0 \%$ for benzodiazepine use).

\section{Hypnotics Use and the Risk of Cancer by Type}

Hypnotics use showed the strongest association with the risk of esophagus carcinoma (Table 4). The risk of renal, prostate, liver, stomach, pancreatic, and lung cancer increased with the use of hypnotics. There was a marginal association between hypnotics use and increased risk of breast and brain cancer; in contrast, no significant relationship was observed with cervical cancer, ovarian cancer, bladder cancer, colon cancer, and oral cancer. Since only one study focused on benign tumor, ${ }^{12)}$ we did not conduct subgroup meta-analyses by the presence of malignancies for each type of cancer.

\section{Assessment of Publication Bias}

No substantial publication bias was found in the selected studies (Begg's funnel plot was symmetric; and Egger's test, $\mathrm{P}=0.60$ ).

\section{DISCUSSION}

In the current meta-analysis of six observational epidemiological stud-

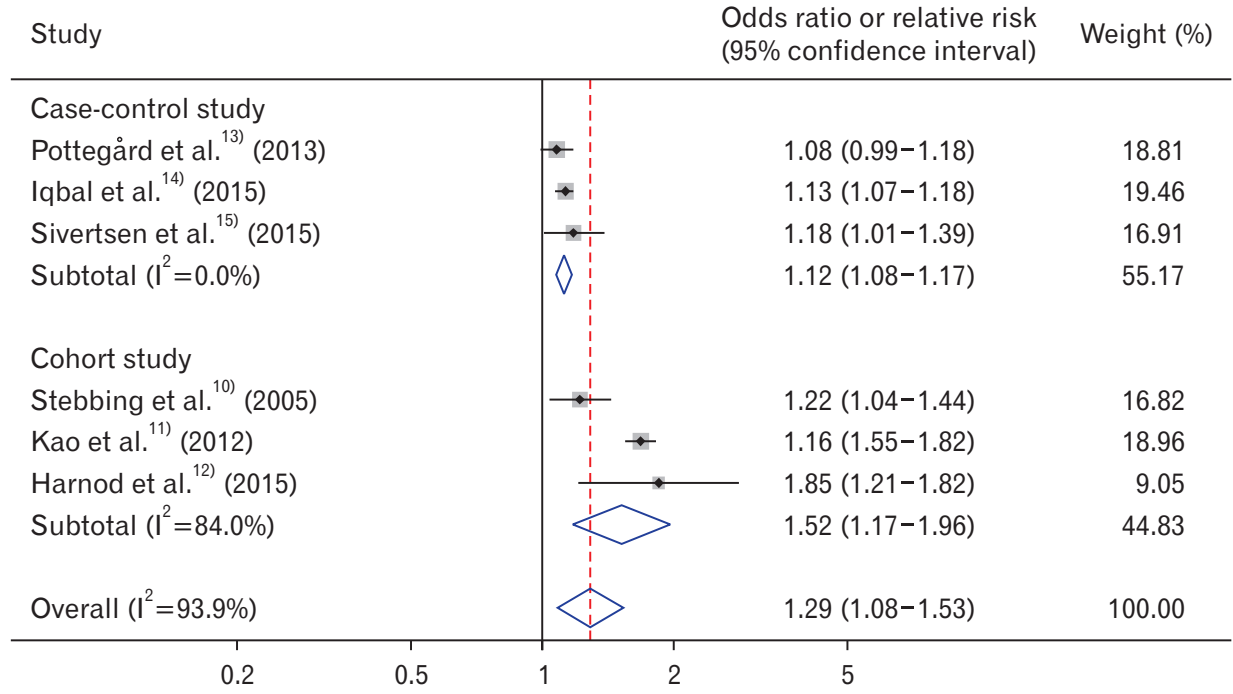

Figure 2. Use of hypnotics and risk of cancer in a random-effects meta-analysis of observational studies by study design $(n=6)$. 
Table 4. Association between hypnotics use and the risk of cancer in subgroup meta-analyses

\begin{tabular}{|c|c|c|c|c|}
\hline Factors & No. of studies & $\begin{array}{l}\text { Summary odds ratio or relative risk } \\
(95 \% \text { confidence interval) }\end{array}$ & Heterogeneity, $\left.\right|^{2}(\%)$ & Model used \\
\hline All & 6 & $1.29(1.08-1.53)$ & 93.9 & Random-effects \\
\hline \multicolumn{5}{|l|}{ Type of cancer } \\
\hline Breast cancer* & 4 & $1.18(1.00-1.38)$ & 81.2 & Random-effects \\
\hline Cervical cancer & 4 & $0.94(0.73-1.21)$ & 53.6 & Random-effects \\
\hline Ovarian cancer & 3 & $1.04(0.89-1.23)$ & 1.1 & Random-effects \\
\hline Brain cancer* & 3 & $1.55(1.00-1.39)$ & 78.1 & Random-effects \\
\hline Renal cancer & 3 & $1.47(1.10-1.96)$ & 66.8 & Random-effects \\
\hline Prostate cancer & 3 & $1.24(1.02-1.51)$ & 75.6 & Random-effects \\
\hline Bladder cancer & 3 & $1.27(0.97-1.66)$ & 80.0 & Random-effects \\
\hline Liver cancer & 3 & $1.53(1.08-2.17)$ & 88.6 & Random-effects \\
\hline Colon cancer & 3 & $1.12(0.97-1.31)$ & 72.7 & Random-effects \\
\hline Esophagus cancer & 3 & $1.57(1.31-1.89)$ & 0.0 & Random-effects \\
\hline Stomach cancer & 3 & $1.18(1.05-1.33)$ & 4.6 & Random-effects \\
\hline Pancreas cancer & 2 & $1.39(1.17-1.64)$ & 0.0 & Random-effects \\
\hline Lung cancer & 4 & $1.36(1.12-1.65)$ & 83.8 & Random-effects \\
\hline Oral cancer & 2 & $1.54(0.69-3.44)$ & 90.6 & Random-effects \\
\hline \multicolumn{5}{|l|}{ Gender } \\
\hline Female only & 1 & $1.67(1.49-1.87)$ & NA & NA \\
\hline Male only & 1 & $1.70(1.51-1.91)$ & NA & NA \\
\hline Male \& female & 6 & $1.29(1.08-1.53)$ & 93.9 & Random-effects \\
\hline \multicolumn{5}{|l|}{ Region } \\
\hline Europe & 3 & $1.13(1.05-1.21)$ & 5.9 & Random-effects \\
\hline Asia & 3 & $1.48(1.05-2.07)$ & 97.2 & Random-effects \\
\hline \multicolumn{5}{|c|}{ Duration of hypnotics use } \\
\hline$\geq 1 \mathrm{y}$ & 4 & $1.17(1.04-1.32)$ & 94.9 & Random-effects \\
\hline$<6 \mathrm{mo}$ & 2 & $1.44(1.06-1.97)$ & 91.6 & Random-effects \\
\hline \multicolumn{5}{|l|}{ Types of hypnotics } \\
\hline Zolpidem & 4 & $1.34(1.06-1.70)$ & 96.3 & Random-effects \\
\hline Zopiclone & 3 & $1.11(1.04-1.20)$ & 37.3 & Random-effects \\
\hline Benzodiazepines & 2 & $1.15(1.11-1.18)$ & 0.0 & Random-effects \\
\hline \multicolumn{5}{|l|}{ Cumulative yearly dose } \\
\hline Lower & 3 & $1.03(1.01-1.05)$ & 0.0 & Random-effects \\
\hline Moderate & 2 & $1.43(0.82-2.49)$ & 98.8 & Random-effects \\
\hline Highest & 3 & $1.44(0.85-2.44)$ & 98.7 & Random-effects \\
\hline \multicolumn{5}{|c|}{ Case-control study design } \\
\hline Population-based & 5 & $1.31(1.07-1.59)$ & 95.1 & Random-effects \\
\hline Hospital-based & 1 & $1.22(1.04-1.44)$ & NA & NA \\
\hline \multicolumn{5}{|l|}{ Methodological quality } \\
\hline Low quality & 2 & $1.20(1.07-1.34)$ & 0.0 & Random-effects \\
\hline High quality & 4 & $1.34(1.06-1.70)$ & 96.3 & Random-effects \\
\hline
\end{tabular}

NA, not applicable.

*Marginally significant.

ies, the results showed that the use of hypnotics was associated with an increased risk of cancer compared to non-use. Subgroup metaanalyses by diverse confounders revealed similar results.

There are several possible mechanisms by which hypnotics could affect cancer risk. First, patients using hypnotics are likely to have an increased rate of infection. Some studies have linked benzodiazepine use to several causes of infection that can increase the incidence of cancer. Use of benzodiazepines can facilitate advances in numerous viral infections that could increase the risk of cancer. In a prospective cohort study with 17-year follow-up, ${ }^{16)}$ the use of benzodiazepine significantly increased the risk of hepatitis $\mathrm{C}$ virus (HCV) seroconversion.
Hepatocellular carcinoma (HCC) can result from chronic hepatitis C. A 15-year prospective cohort study of HCV patients showed that the cumulative risk for HCC increased from $6.4 \%$ for low-levels of HCV RNA to $14.7 \%$ for high-levels of HCV RNA $\left.(\mathrm{P}<0.001) .{ }^{17}\right)$

Human immunodeficiency virus (HIV) is a possible factor that links benzodiazepine use to an increased risk of carcinoma. In 1,682 participants without HIV infection at baseline, ${ }^{18)}$ benzodiazepine use was significantly related with an elevated rate of HIV seroconversion in the 80-month study period (RR, 1.50; 95\% CI, 1.01-2.24). Subjects with HIV infection are more susceptible to human papilloma virus (HPV) infection. ${ }^{19)}$ Additionally, HIV could alter the usual immune response 


$$
\text { Study }
$$

Odds ratio or relative risk ( $95 \%$ confidence interval)
Weight (\%)

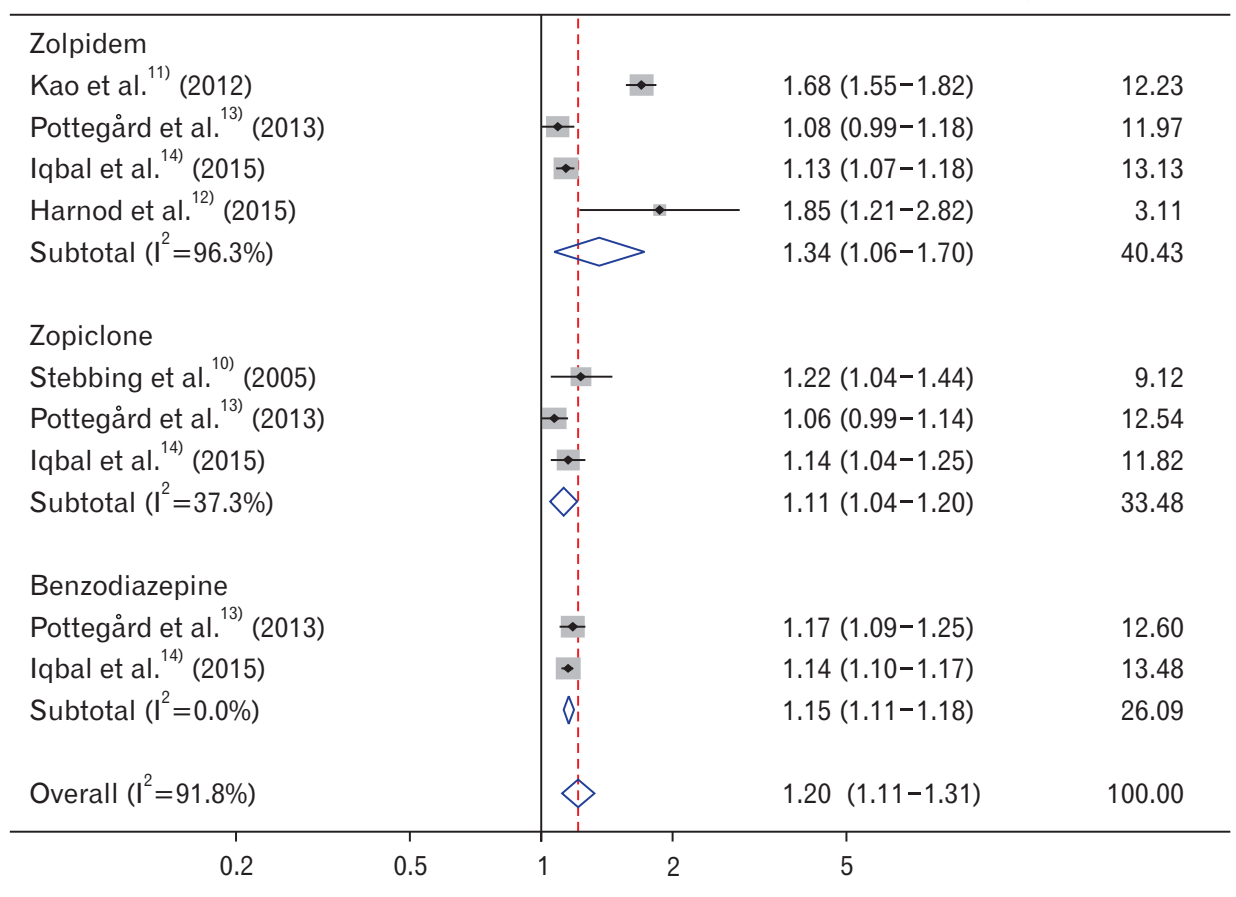

Figure 3. The association between use of hypnotics and risk of cancer in a randomeffects meta-analysis of observational studies by type of hypnotics $(n=6)$. to HPV and boost occurrence of squamous intraepithelial lesions in the cervix. ${ }^{19)}$ In a 10 -year follow-up study of 310,000 acquired immune deficiency syndrome patients (257,605 men and 51,760 women), HIV infection showed a trend of increased association with the occurrence of cancer related to HPV such as anal cancer in addition to cervix cancer. ${ }^{20)}$ Likewise, Zolpidem use could be a trigger factor in viral infection associated with the risk of cancer. In a meta-analyses inspecting the association between hypnotics and infection, zolpidem use showed a risk ratio of infection of 1.99 (95\% CI, 1.21-3.26) including herpes simplex virus (HSV) infection. ${ }^{21)}$ HSV infection eventually may increase the risk of cervical cancer, according to a meta-analyses of 14 casecontrol studies (OR, 1.37; 95\% CI, 1.12-1.69). ${ }^{22)}$

Inflammation is the second possible biological mechanism. Since chronic inflammation might be associated with hypnotics use, inflammation can be a pivotal factor as a link between the use of sleep medication and the risk of cancer development. Hypnotics including alprazolam, zolpidem and zopiclone application can cause chronic inflammation via cotton-wool granuloma formation. ${ }^{23)}$ In addition to the gamma-aminobutyric acid A receptor complex in the central nervous system, benzodiazepine peripheral-type binding sites (PBRs) are localized in immune cells and carcinoma cells. ${ }^{24)} \mathrm{PBR}$ density is possibly associated with the progression of cancer in these cell types. Elevated levels of inflammatory cytokines such as interleukin-1 and tumor necrosis factor could worsen the course of disease in non-Hodgkin's lymphoma and gastric cancer, respectively. ${ }^{25)}$ Therefore, inflammation attributable to the use of hypnotics might mediate cancer development.

Third, people taking hypnotics could experience more medical care than non-users, thereby receiving greater surveillance for cancer detection in contrast to non-users. Last, by reverse causality, patients who are already at risk for cancer may have a greater tendency to start using hypnotics than those not at risk for cancer. Patients with psychiatric disorder including anxiety, depression, or insomnia tend to take hypnotics more than average. ${ }^{26)}$ Sleep disturbance is also related to various diseases such as cardiovascular disorder, gastrointestinal disorder, and chronic obstructive pulmonary disease. ${ }^{27)}$ About $60 \%-70 \%$ of cancer patients suffer from comorbidities including hypertension, diabetes, cardiovascular disease, pulmonary disease, or psychologic disorder. ${ }^{28)}$ Only two studies in our meta-analysis adjusted for possible confounding factors such as hypertension, diabetes, cardiovascular disease, chronic obstructive pulmonary disease, and inflammatory bowel disease. ${ }^{11,13)}$ Thus, many diseases accompanying the use of hypnotics may lead to cancer development instead of hypnotics use itself.

Our meta-analysis has several limitations. First, we only included observational epidemiological studies because there have been few published randomized controlled trials on this topic. Case-control studies are usually more sensitive to recall bias and selection bias than cohort studies, which might result in spurious associations. Also, cohort studies have a lower level of evidence than randomized controlled trials. Another limitation is that a small fraction of the included studies adjusted tobacco smoking and alcohol drinking as confounding factor(s), which are both established factors for the risk of carcinoma; five studies adjusted tobacco smoking as a confounding factor, and four studies adjusted alcohol drinking as a confounding factor. Thus, we were unable to exclude the confounding efficacy of important factors such as smoking or alcohol drinking on the association between 
hypnotics use and the risk of cancer.

In conclusion, meta-analysis of observational epidemiological studies showed that hypnotics use was associated with an increased risk of cancer. However, this association should be cautiously interpreted because substantial heterogeneity was present as high value of I square (I square value was $93.9 \%$, high above $50 \%$ in a main meta-analysis.). Larger prospective cohort studies or randomized controlled studies providing a higher level of evidence are required to confirm the present findings.

\section{CONFLICT OF INTEREST}

No potential conflict of interest relevant to this article was reported.

\section{REFERENCES}

1. Nomura K, Yamaoka K, Nakao M, Yano E. Impact of insomnia on individual health dissatisfaction in Japan, South Korea, and Taiwan. Sleep 2005;28:1328-32.

2. Ohayon MM, Caulet M, Priest RG, Guilleminault C. Psychotropic medication consumption patterns in the UK general population. J Clin Epidemiol 1998;51:273-83.

3. Miyawaki I, Moriyasu M, Funabashi H, Yasuba M, Matsuoka N. Mechanism of clobazam-induced thyroidal oncogenesis in male rats. Toxicol Lett 2003;145:291-301.

4. Kim DH, Lee JT, Lee IK, Ha JH. Comparative anticancer effects of flavonoids and diazepam in cultured cancer cells. Biol Pharm Bull 2008;31:255-9.

5. Halapy E, Kreiger N, Cotterchio M, Sloan M. Benzodiazepines and risk for breast cancer. Ann Epidemiol 2006;16:632-6.

6. Harnod T, Lin CL, Sung FC, Kao CH. An association between benzodiazepine use and occurrence of benign brain tumors. J Neurol Sci 2014;336:8-12.

7. Wells GA, Shea B, O'Connell D, Peterson J, Welch V, Losos M, et al. The Newcastle-Ottawa Scale (NOS) for assessing the quality of nonrandomised studies in meta-analyses [Internet]. Ottawa (ON): Ottawa Hospital Research Institute [cited 2016 Mar 2]. Available from: http:// www.ohri.ca/programs/clinical_epidemiology/oxford.html.

8. Higgins JP, Thompson SG. Quantifying heterogeneity in a meta-analysis. Stat Med 2002;21:1539-58.

9. Borenstein M, Hedges LV, Higgins JP, Rothstein HR. A basic introduction to fixed-effect and random-effects models for meta-analysis. Res Synth Methods 2010;1:97-111.

10. Stebbing J, Waters L, Davies L, Mandalia S, Nelson M, Gazzard B, et al. Incidence of cancer in individuals receiving chronic zopiclone or eszopiclone requires prospective study. J Clin Oncol 2005;23:8134-6.

11. Kao CH, Sun LM, Liang JA, Chang SN, Sung FC, Muo CH. Relationship of zolpidem and cancer risk: a Taiwanese population-based cohort study. Mayo Clin Proc 2012;87:430-6.

12. Harnod T, Li YF, Lin CL, Chang SN, Sung FC, Kao CH. Higher-dose uses of zolpidem will increase the subsequent risk of developing be- nign brain tumors. J Neuropsychiatry Clin Neurosci 2015;27:e107-11.

13. Pottegard A, Friis S, Andersen M, Hallas J. Use of benzodiazepines or benzodiazepine related drugs and the risk of cancer: a populationbased case-control study. Br J Clin Pharmacol 2013;75:1356-64.

14. Iqbal U, Nguyen PA, Syed-Abdul S, Yang HC, Huang CW, Jian WS, et al. Is long-term use of benzodiazepine a risk for cancer? Medicine (Baltimore) 2015;94:e483.

15. Sivertsen B, Salo P, Pentti J, Kivimaki M, Vahtera J. Use of sleep medications and risk of cancer: a matched case-control study. Sleep Med 2015;16:1552-5.

16. Bach P, Walton G, Hayashi K, Milloy MJ, Dong H, Kerr T, et al. Benzodiazepine use and hepatitis $\mathrm{C}$ seroconversion in a cohort of persons who inject drugs. Am J Public Health 2016;106:1067-72.

17. Lee MH, Yang HI, Lu SN, Jen CL, Yeh SH, Liu CJ, et al. Hepatitis C virus seromarkers and subsequent risk of hepatocellular carcinoma: longterm predictors from a community-based cohort study. J Clin Oncol 2010;28:4587-93.

18. Ickowicz S, Hayashi K, Dong H, Milloy MJ, Kerr T, Montaner JS, et al. Benzodiazepine use as an independent risk factor for HIV infection in a Canadian setting. Drug Alcohol Depend 2015;155:190-4.

19. Parkin DM. The global health burden of infection-associated cancers in the year 2002. Int J Cancer 2006;118:3030-44.

20. Frisch M, Biggar RJ, Goedert JJ. Human papillomavirus-associated cancers in patients with human immunodeficiency virus infection and acquired immunodeficiency syndrome. J Natl Cancer Inst 2000;92:1500-10.

21. Joya FL, Kripke DF, Loving RT, Dawson A, Kline LE. Meta-analyses of hypnotics and infections: eszopiclone, ramelteon, zaleplon, and zolpidem. J Clin Sleep Med 2009;5:377-83.

22. Cao S, Gan Y, Dong X, Lu Z. Herpes simplex virus type 2 and the risk of cervical cancer: a meta-analysis of observational studies. Arch Gynecol Obstet 2014;290:1059-66.

23. Zdrinca M, Muțiu G, Bogdan M, Dobjanschi L, Antonescu A, Mos I, et al. Effects of Alprazolam, Zolpidem and Zopiclone, and of chronic inflammation on peripheral experimental algesia in Wistar rats. Rom J Morphol Embryol 2011;52(1 Suppl):471-4.

24. Han Z, Slack RS, Li W, Papadopoulos V. Expression of peripheral benzodiazepine receptor (PBR) in human tumors: relationship to breast, colorectal, and prostate tumor progression. J Recept Signal Transduct Res 2003;23:225-38.

25. El-Omar EM, Carrington M, Chow WH, McColl KE, Bream JH, Young HA, et al. Interleukin-1 polymorphisms associated with increased risk of gastric cancer. Nature 2000;404:398-402.

26. DiNapoli EA, Bramoweth AD, Cinna C, Kasckow J. Sedative hypnotic use among veterans with a newly reported mental health disorder. Int Psychogeriatr 2016;28:1391-8.

27. Wallander MA, Johansson S, Ruigomez A, Garcia Rodriguez LA, Jones R. Morbidity associated with sleep disorders in primary care: a longitudinal cohort study. Prim Care Companion J Clin Psychiatry 2007;9:338-45.

28. Ogle KS, Swanson GM, Woods N, Azzouz F. Cancer and comorbidity: redefining chronic diseases. Cancer 2000;88:653-63. 